\title{
Sentetik Pap-Smear Hücre Çekirdeği Üretiminde Üretici Çekişmeli Ağların Kullanılması
}

\author{
Sara Altun ${ }^{1 *}$, M. Fatih Talu ${ }^{2}$ \\ ${ }^{1}$ İnönü Üniversitesi, Mühendislik Fakültesi, Bilgisayar Mühendisliği Bölümü, Malatya, Türkiye (ORCID: 0000-0003-2877-7105) \\ 2 İnönü Üniversitesi, Mühendislik Fakültesi, Bilgisayar Mühendisliği Bölümü, Malatya, Türkiye (ORCID: 0000-0003-1166-8404)
}

(Illk Geliş Tarihi 13 Aralık 2020 ve Kabul Tarihi 20 Nisan 2021)

(DOI: 10.31590/ejosat.840114)

ATIF/REFERENCE: Altun, S. \& Talu, M. F. (2020). Sentetik Pap-Smear Hücre Çekirdeği Üretiminde Üretici Çekişmeli Ağların Kullanılması. Avrupa Bilim ve Teknoloji Dergisi, (23), 781-786.

\section{$\ddot{O} \mathbf{z}$}

Sentetik görüntü üretimi geçmişten günümüze kadar araştırma alanı olmuştur. Çeşitli algoritmalar ile sentetik (sahte) görüntü üretimi yapılmaktadır. İncelenen sentetik görüntü üretme yöntemleri derin öğrenmeye dayanan üretici çekişmeli ağlar (GANs)'dır. GAN'lar üretici ve ayrıştırıcı olmak üzere iki sinir ağına sahiptir. Üretici ağ sentetik görüntü ya da sinyal üretirken; ayrıştırıcı ağ orijinal görüntü ya da sinyal ile üretilmiş sentetik görüntünün ya da sinyalin benzerliğini olasılıksal olarak ölçmektedir. GAN yöntemlerinden Döngüsel Üretici Çekişmeli Ağ ( CycleGAN ) ve Görüntüden Görüntüye Çeviren Ağ (Pix2Pix) yöntemleri sentetik görüntü üretirken görüntüden görüntüye çeviri yapılabilme yeteneğine sahip olduğundan hücre çekirdeği üretirken uygun yöntemler olarak belirlenmiştir. CycleGAN, bir üretici ve bir ayrıştıııcı ağa sahiptir. Üretici, sahte görüntüleri üretirken; ayrıştırıcı, sahte görüntüler ile gerçek görüntüleri ayırt etmeye çalışır. CycleGAN, bir görüntüyü $X$ kaynak alanından eşleştirilmiş örneklerin yokluğunda bir hedef alan $Y$ 'ye dönüştüren öğrenme yaklaşımı sunulur. Bu model iki "otokodlayıcı” eğitimi olarak görülebilir. Bir otokodlayıcıyı $F \circ G: X$ $\rightarrow X$ ile bir başka otokodlayıcı olan $G \circ F: Y \rightarrow Y$ ile ortaklaşa öğrenir. Pix2Pix'in girişi bir görüntüdür. Pix2Pix, giriş görüntüsünden çıktı görüntüsüne dönüşümü eğitir. Pix2Pix, bir tane sentetik görüntü üreten üretici ağa ve bu sentetik görüntü ile gerçek görüntüyü ayırt edebilecek olan ayrıştırıcı ağa sahiptir. Bu çalışmada, 256x256 boyutunda görüntüler kullanılmış olup 256x256 boyutunda sonuçlar elde edilir. İki yöntemin zaman ve benzerlik indeksleri açısından karşılaştırması yapılıp verimliliği incelenmiştir. Sonuçlar tablo ve şekil olarak gösterilmiştir. Uygulama için MATLAB 2019b kullanılmıştır. Görüntüden görüntüye dönüşümde GAN yöntemlerinin verimli sonuçlar verdiği gözlemlenmektedir. Medikal görüntü üretirken deneysel sonuçlara göre CycleGAN yöntemi ile Pix2Pix yöntemi kıyaslandığında istenilen sonuca ulaşma bakımından Pix2Pix yöntemi tercih edilebilir.

Anahtar Kelimeler: Sentetik Görüntü Üretimi, Üretici Çekişmeli Ağlar, CycleGAN, Pix2Pix.

\section{The Use of Generator Adversarial Networks in Synthetic Cell Nucleus Production}

\begin{abstract}
Synthetic image production has been an area of research from the past to the present. Synthetic (fake) images are produced with various algorithms. The synthetic image generation methods examined are generative adversarial networks (GANs) based on deep learning.
\end{abstract}

\footnotetext{
* Sorumlu Yazar: Sara ALTUN, İnönü Üniversitesi, Mühendislik Fakültesi, Bilgisayar Mühendisiliği Bölümü, Malatya, Türkiye, ORCID: 00000003-2877-7105, sara.altun@inonu.edu.tr
} 
GANs have two neural networks, a generator and a discriminator. When the generator network generates synthetic images or signals; the discriminator network measures probabilistically the similarity of the synthetic image or signal generated with the original image or signal. Cycle-consistent Generating Adversarial Network (CycleGAN) and Image-to-Image Converting Network (Pix2Pix) methods, which are among the GAN methods, have been determined as suitable methods while producing a cell nucleus because they have the ability to translate from image to image while producing synthetic images. CycleGAN has two network of a generator and a discriminator. When the generator produces fake images; The discriminator tries to distinguish fake images from real images. CycleGAN presents a learning approach that transforms an image from the source field into a target area in the absence of paired samples. This model can be viewed as two "autocoder" training. Learns an autocoder jointly with $F \circ G: X \rightarrow X$ and another autocoder, $G \circ F: Y \rightarrow Y$. Pix2Pix's input is an image. Pix2Pix trains the conversion from input image to output image. Pix2Pix has one synthetic image generating network and a discriminating network that can distinguish the synthetic image from the real image. In this study, images of 256x256 are used and results of 256x256 are obtained. The efficiency of the two methods was compared in terms of time and similarity indexes and examined. Results are shown in tables and figures. MATLAB 2019b was used for the application. It is observed that GAN methods give efficient results in image-to-image conversion. When producing medical images, the Pix2Pix method can be preferred in terms of achieving the desired result when comparing the CycleGAN method with the Pix2Pix method according to the experimental results.

Keywords: Synthetic Image Generation, Generator Adversarial Networks, CycleGAN, Pix2Pix.

\section{Giriş}

Sentetik görüntü üretimi, gerçek olan verilerden bilgisayar ve benzeri ortamlardan aynısına benzer sahte görüntüler üretme işlemidir. Sentetik veriler, verinin sayısını arttırmak, sanal gerçekliği sağlamak ve araştırmacıların birçok konuda incelemeyapabilmesi için geniş bir alana sahiptir.

Üretici Çekişmeli Ağlar (Generative Adversarial Networks GANs ), makine öğrenme modellerinden bir tanesidir. GANlar sahte ama neredeyse gerçek denilecek şekilde veriler üretme yeteneğine sahiptir (Sara ve Fatih, 2019). Üretici ve ayrıştırıcı ağdan oluşmuşlardır. Üretici ağ gerçeğe benzeyen sahte görüntü üretir. Ayrıştırıcı ağ ise gerçek ile sahte görüntü arasında ayrım yapmaya çalışır. Ayrıştırıcıyı bir sınıflandırıcı olarak tanımlayan geleneksel GANlar, sigmoid çapraz entropi kaybı işlevini benimsemektedir (Barışkan vd., 2020). Bu fikirden yola çıkılarak görüntüden görüntüye dönüşüm yapan GAN yöntemlerinden olan Pix2Pix ve CycleGAN yöntemleri mevcuttur (Zhu et al., 2017; Isola et al., 2017).

Görüntüden görüntüye dönüştürme fikri, en az bir girdi-çıktı eğitim görüntü çifti üzerinde parametrik olmayan doku modelini (Efros and Leung) kullanan Hertzmann ve arkadaşlarının Görüntü Analojilerine dayanmaktadır (Hertzmann et al.,2001). Güncel yaklaşımlar, CNN'leri kullanarak parametrik dönüştürme işlevini öğrenmek için girdi-çıktı örneklerinden oluşan veri kümesi kullanır (ör. Long et al., 2015). CycleGAN yaklaşımı, Isola ve diğerlerinin "Pix2Pix" çerçevesi (Isola et al., 2017) üzerine kuruludur. girdiden çıktı görüntülerine kadar bir eşlemeyi öğrenmek için koşullu üretken bir düşman ağı kullanır (Goodfellow et al.,2014). Taslaklardan veya özniteliklerden (Sangkloy et al., 2017) ve anlamsal düzenlerden (Karacan et al., 2016) fotoğraflar üretmek gibi çeşitli görevlere benzer fikirler uygulanmıştır. CycleGAN önceki çalışmalardan farklı olarak, eşleştirilmiş eğitim örnekleri olmadan eşlemeyi öğrenir.

$\mathrm{Bu}$ çalışmada, aynı veriseti üzerinde Döngüsel Üretici Çekişmeli Ağ ( CycleGAN ) ve Görüntüden Görüntüye Çeviren Ağ (Pix2Pix) yöntemlerinin sentetik görüntü üretmede doğruluk sonuçları ve görsel sonuçları üzerinde ne gibi etkileri olduğu araştırılmıştır. Bu iki GAN yöntemi için aynı başlangıç koşulları belirlenmiştir. $\mathrm{Bu}$ eşit koşullar altında generatör maliyeti, diskriminatör maliyeti ve doğruluk sonuçları deneysel sonuçlarda karşılaştırılmıştır.

$\mathrm{Bu}$ çalışma ile CycleGAN ve Pix2Pix yönemleri kullanılarak yapılacak araştırmalar için ön bilgi niteliğinde bir çalışma gerçekleştirilmiştir. $\mathrm{Bu}$ çalışmanın organizasyonu şu şekilde planlanmıştır: ikinci bölümde kullanılan GAN yöntemleri ile ilgili genel bilgiler verilmektedir. Üçüncü bölümde yapılan çalışma detaylı bir şekilde açıklanmaktadır, dördüncü bölümde ise deneysel sonuçları sunulmaktadır.

\section{Materyal ve Metot}

Üretici çekişmeli ağlardan sentetik görüntü üretimi için uygun olan CycleGAN ve Pix2Pix yöntemlerine yer verilmektedir.

\subsection{Pix2Pix}

Pix2Pix, DCGAN'ın geliştirilmiş bir sürümüdür (Sato et al., 2018). Standart DCGAN'dan farkı, üretici ağa gelen girişdir. Standart DCGAN'ın girişi bir vektördür (ör. 100 boyutunda ) ancak Pix2Pix'in girişi görüntüdür. Pix2Pix, giriş görüntüsünden çıktı görüntüsüne dönüşümü eğitir (ör. Gri tonlamadan renkli görüntüye).

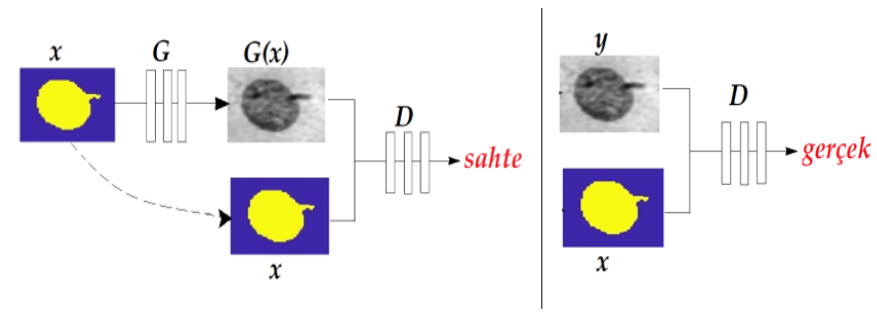

Şekil 1. Hücre Çekirdeği Oluşturulurken Pix2Pix’in Genel Yapısı 
Pix2Pix, girdi ve çıktı görüntüleri arasındaki dönüşümü eğitebildiği için, sentetik görüntü üretmede kullanılabilir. Pix2Pix, üretici ve ayrıştırıcı ağdan oluşur. Üretici, giriş görüntüsünden bir çıktı görüntüsü üretir. Ayrıştırıcı, üretici ağın üretmiş olduğu çıktı görüntüsünün gerçek mi yoksa sahte mi olduğunu sınıflandırır. Diğer bir deyişle üretici, kaynak görüntü $\mathrm{x}$ ve rasgele gürültü vektörü z'den hedef görüntü y'ye, yani $\{x, z$ $\rightarrow y$ \} bir eşlemeyi öğrenir. Ayrıştırıcı, y |x etiketini gerçek veya sahte olarak ayırt eder. İki ağ, düşmanca bir ilişkiye sahiptir.

Şekil 1'de, üretici ağın çıkış görüntüsünü bir giriş görüntüsünden elde ettiği ve ayrıştırıcı ağın bunu gerçek veya sahte olarak sınıflandırdığı görülmektedir. Hücre çekirdeğinin maskesi üretici ağın (generatör-G) girişine verilmektedir. Üretici ağın iç kısmında konvolusyon vb. ara işlemlerden geçirilerek yeni sahte görüntü elde edilir. Ayrıştırıcı ağ (discriminator-D) ise gerçek ve sahte görüntüyü ayırt etmeye çalışır. Durma kriteri, ayrıştırıcı ağın ayırt etme olasılığı düştüğünde sonlanır. Denklem 1'de ise Şekil 1'de anlatılan Pix2Pix'in asıl amacının formülleştirilmiş formuna yer verilmiştir. $\lambda$,iki hedefin göreceli önemini kontrol eder.

$$
G^{*}=\underset{G}{\operatorname{argmin}} \max _{D} \mathcal{L}_{C G A N}(G, D)+\lambda \mathcal{L}_{L 1}(G)
$$

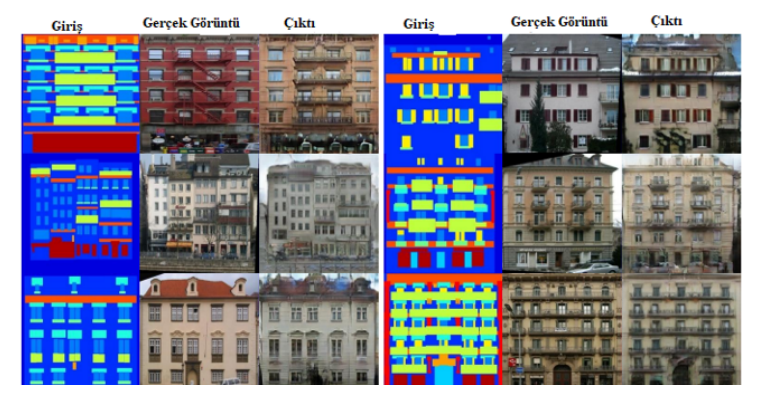

Şekil 2. Cephe Fotoğraflarında Pix2Pix Uygulama Sonuçları (Isola et al.,2017).

Pix2Pix yapı olarak ayrıştırıcı ağda CNN ve üretici ağ olarak U-net kullanılır. U-net, bir tür kodlayıcı-kod çözücü CNN'dir. Temel fark, kodlayıcıdan kod çözücüye giden yollardır. Yollar, kodlayıcı ile küçük nesnelerin kaybolmasını önler. Başka bir deyişle, çok ölçekli bilgi, sonuç görüntüsünü etkili bir şekilde oluşturmak için kullanılır. Ayrıştırıcı ağı, Pix2Pix'te üretici ağın verimliliğini değerlendirir. Ancak bu ağlar birbirlerinden bağımsızdırlar ve ayrıştırıcıdaki bilgiler üretici ağda etkin bir şekilde kullanılmamaktadır. Bu nedenle, Şekil 2'de görüldüğü gibi temel gerçeğe benzer iyi sentetik görüntü sonucu elde etmek için üretici ağ da ayrıştırıcı ağda özellik haritalarını kullanılır (Isola et al.,2017).

Pix2Pix'in geleneksel GAN ile önemli farklılıkları olduğunu belirtmekte fayda var. Örneğin, Pix2Pix ayrımcısının girişi tek bir görüntü yerine bir çift görüntüdür, Pix2Pix'in ayrıştırıcısı gerçek görüntüyü sahte görüntülerden ayırmak için PatchGAN yapısını kullanır (Wang et al., 2018) .

\subsection{CycleGAN}

Görüntüden görüntüye dönüşüm, hedefin hizalanmış görüntü çiftlerini içeren bir eğitim seti kullanarak bir giriş görüntüsü ile çıkış görüntüsü arasındaki eşlemeyi öğrenmek olduğu bir görme ve grafik problemleri sınıfıdır. Bununla birlikte birçok işlem için eşleştirilmiş eğitim verileri kullanılamaz.

Niteliksel sonuçlar, koleksiyon stili aktarımı, nesne değişimi, sezon aktarımı, fotoğraf geliştirme vb. dahil olmak üzere eşleştirilmiş eğitim verilerinin bulunmadığı çeşitli işlemler de sunulur. CycleGAN yöntemi ile koleksiyon tarzı aktarım, mevsim geçişleri, çizimlerden fotoğraf üretimi, fotoğraf geliştirme, Gatys ve arkadaşları ile karşılaştırma(Gatys et al., 2016) yapılmıştır(Zhu et al.,2017). Önceki birkaç metotla yapılan nicel karşılaştırmalar, CycleGAN yaklaşımının üstünlüğünü göstermektedir. Şekil 3'de CycleGAN yönteminin zebradan ata, gerçek görüntüden çizim görüntüsüne ve tam tersi örneklere yer verilmiştir.
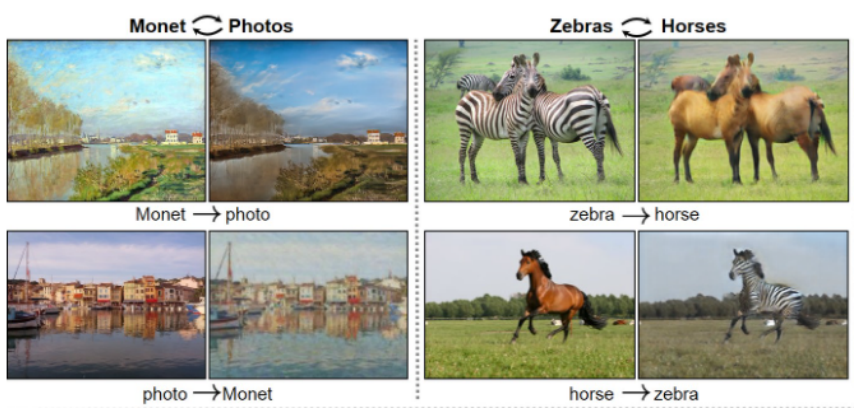

Şekil 3. CycleGAN Uygulama Sonuçları (Zhu et al., 2017)

CycleGAN yönteminde de üretici giriş olarak bir görüntü alır ve bunu işlemlerden geçirerek yeni görüntü üretir. Şekil 3 'te gösterildği gibi işlem döngüsel olarak gerçekleşir.

Şekil 4'te CycleGAN yöntemi görsel açıdan incelenmiştir. Görüntüyü $X$ kaynak alanından eşleştirilmiş örneklerin yokluğunda bir hedef alan $Y$ ye çevirmeyi öğrenme yaklaşımı sunulmaktadır. Hedef, $G: X \rightarrow Y$ eşlemesini öğrenmektir, öyle ki $G(X)$ den görüntülerin dağılımı, bir kayıp kaybı kullanarak $Y$ dağılımından ayırt edilemez. Bu haritalama oldukça kısıtlı olduğundan birleştirilir. $F: Y \rightarrow X$ tersine eşleme ve $F(G(X)) \approx$ $X$ (ve bunun tersi) zorlamak için döngüsel tutarlılık maliyetini sağlar.

CycleGAN yönteminin amacı Denklem 2 ve Denklem 3'de gösterilmiş (Zhu et al., 2017); Şekil 4 ile ne anlama geldiği açıklanmıştır.

$$
\begin{aligned}
\mathcal{L}\left(G, F, D_{X}, D_{Y}\right)= & \mathcal{L}_{G A N}\left(G, D_{Y}, X, Y\right)+\mathcal{L}_{G A N}\left(F, D_{X}, Y, X\right) \\
& +\lambda \mathcal{L}_{c y c}(G, F)
\end{aligned}
$$


$\lambda$,iki hedefin göreceli önemini kontrol eder. Çözülmesi hedeflenen:

$$
G^{*}, F^{*}=\arg \min _{G, F} \max _{D_{X}, D_{Y}} \mathcal{L}\left(G, F, D_{X}, D_{Y}\right)
$$

Herhangi iki sıralanmamış görüntü koleksiyonu $X$ ve $Y$ verildiğinde, algoritma bir görüntüyü otomatik olarak bir görüntüden diğerine çevirmeyi ve bunun tersini öğrenir.

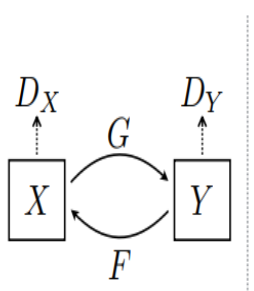

(a)

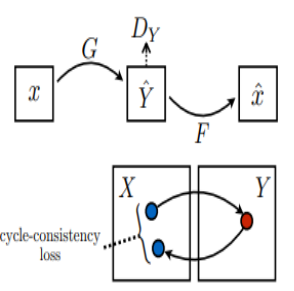

(b)

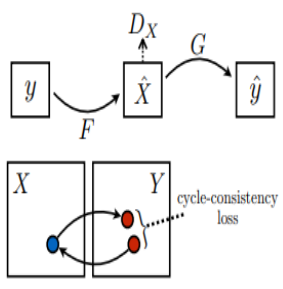

(c)
Şekil 4. CycleGAN Yapısı. (a) Model Tanımlanması (b) Döngü tutarlılığı (c) Döngü Tutarlılığı (Zhu et al., 2017)

\section{Araştırma Sonuçları ve Tartışma}

\subsection{Veri Kümesi}

Veri kümesi olarak hücre çekirdeklerinin bulunduğu 100 adet görüntü kullanılmıştır. Bu veriler alındığı kısımdan her bir hücrede ardışıl görüntü (dip image) olarak depolanmıştır. $\mathrm{Bu}$ görüntülerin her biri ayrıştırılarak tek bir görüntü şekline sahip değere dönüştürülmüştür. Veri kümesindeki birinci sütundaki hücrelerde 100 adet orijinal ve boyutları farklı hücre çekirdeği görüntüleri bulunmaktadır. Veri kümesindeki ikinci sütundaki hücrelerde bulunan görüntüler, orijinal görüntüdeki çekirdeğin bulunduğu kısımda 1 ; çekirdeğin bulunmadığ 1 kısımda 0 bulunan maskeleri barındıran görüntülerdir. Veri kümesinin düzenlenmesi Matlab 2019b kullanılarak yapılmıştır. Şekil 5. (a)'da verisetinin birinci sütununda bulunan orijinal görüntülerden bir tanesi örneklenmektedir. Şekil 5. (b)'de verisetinin ikinci sütununda orijinal görüntülerden elde edilmiş görüntü maskesi verilmektedir.



(a)

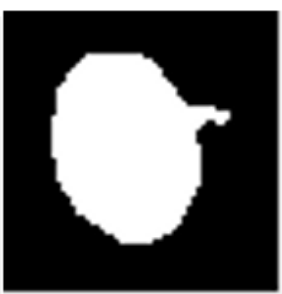

(b)
Şekil 5. (a) Orijinal Çekirdek Görüntüsü (b) Çekirdek Görüntü Maskesi

Görüntüleri daha düzgün bir şekilde karşılaştırabilmek için CycleGAN ve Pix2Pix 256x256'lık giriş görüntüleri ve çıkış görüntüleri kullanılmıştır. İterasyon sayısı 200 olarak verilmiştir. Belirli iterasyon aralıklarındaki ortalama, standart sapmaları ve zamansal karşılaştırmaları yapılmıştır. Belirli iterasyonlardaki sonuç görüntülerine yer verilmiştir.

\subsection{CycleGAN ve Pix2Pix Yöntemlerinin Görsel Karşılaştırılması}

CycleGAN iki yönlü eğitim imkânı sunmaktadır. Pix2Pix yöntemi ise görüntünün iskeleti çıkarılmış şekli ile orjinali arasında eğitim yapmaktadır. Şekil 6'da bir iterasyon için CycleGAN ve Pix2Pix için çalışma şekline yer verilmiştir.

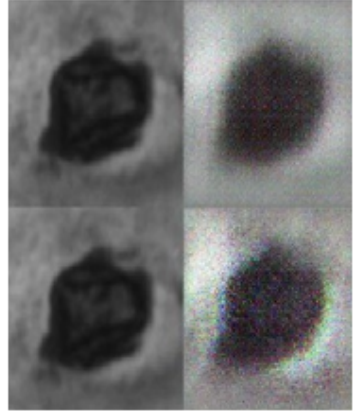

(a)



(b)
Şekil 6. Eğitme Şekilleri. (a) CycleGAN (b) Pix2Pix 
Tablo 1. CycleGAN ve Pix2Pix Eğitim Sonuçları

\begin{tabular}{|c|c|c|c|}
\hline İterasyon Sayısı & Orijinal Hücre Çekirdeği & CycleGAN & Pix2Pix \\
\hline 5 & & & \\
\hline 25 & & & \\
\hline 50 & & & \\
\hline 75 & & & \\
\hline 100 & D & & \\
\hline 125 & & & \\
\hline 150 & & & \\
\hline 175 & & & \\
\hline 200 & & & \\
\hline
\end{tabular}

Zaman açısından incelendiğinde bir iterasyon sonunda geçen süre Pix2Pix için $t \cong 38.3607 \mathrm{~s}$; CycleGAN için $t \cong 98.5609$ s'dir.

Gerçek görüntüye ne kadar benzediğini ölçmek için Jaccard indeksi, Dice indeksi yöntemleri kullanılmıştır. İki set A ve B'nin Jaccard benzerlik katsayısı (birleşme veya IoU üzerinden kesişme olarak da bilinir) şu şekilde ifade edilir:

jaccard $(A, B)=|\operatorname{kesişim~}(A, B)| /|\operatorname{birleşim~}(A, B)|$

Burada $\mid$ A $\mid$, A kümesinin kardinalini temsil eder. Jaccard indeksi aynı zamanda gerçek pozitif (TP), yanlış pozitif (FP) ve yanlış negatif (FN) olarak şu şekilde ifade edilebilir:

$$
\operatorname{jaccard}(\mathrm{A}, \mathrm{B})=\mathrm{TP} /(\mathrm{TP}+\mathrm{FP}+\mathrm{FN})
$$

Dice indeksi Jaccard indeksi ile Denklem 6'da gösterilen ilişkiye sahiptir.

$$
\operatorname{dice}(\mathrm{A}, \mathrm{B})=2 * \operatorname{jaccard}(\mathrm{A}, \mathrm{B}) /(1+\operatorname{jaccard}(\mathrm{A}, \mathrm{B}))
$$

Verilen benzerlik yöntemlerine göre Pix2Pix ve CycleGAN benzerlik sonuçlarına Tablo 2'de gösterilmiştir.

Tablo 2. CycleGAN ve Pix2Pix Benzerlik Sonuçları

\begin{tabular}{ccc}
\hline Yöntemler & CycleGAN & Pix2Pix \\
\hline Jaccard İndeksi & 0.2954874 & 0.3011773 \\
\hline Dice İndeksi & 0.4561795 & 0.4629305 \\
\hline
\end{tabular}




\section{Sonuç}

Bu makalede, sentetik görüntü üretme yeteneğine sahip olan GAN yöntemlerinden Pix2Pix ve CycleGAN yöntemleri incelenmiştir. Orjinal yani gerçek görüntüye benzerlik açısından ve zaman açısından karşılaştırma yapılmıştır. Deneysel sonuçlar incelendiğinde Pix2Pix yöntemi daha az iterasyon ile gerçek görüntüye daha yakın sonuç elde edebilmiş̧ir. Eğitim sürecinde geçen zaman kontrol edildiğinde Pix2Pix yönteminin $\boldsymbol{t} \cong \mathbf{3 8 . 3 6 0 7 s}$ ile daha verimli olduğu gözlemlenmiștir. Benzerlik metriği olarak Jaccard ve Dice indekslerine karşılaştırma yapılmıştır. Pix2Pix yönteminin gerçek görüntüye benzerlik oranı Tablo 2'de görüldüğ̈̈ üzere daha yüksek olduğu gözlemlenmiştir. CycleGAN yöntemi ile üretilen görüntülerin gerçek görüntülere benzerliği Pix2Pix yöntemi ile kıyaslandığında daha düşük olduğu gözlemlenmektedir. Pix2Pix yöntemi gerçek görüntülere daha benzer görüntüler elde ettiğinden tercih edilebilir. Medikal görüntü üretirken görüntüden görüntüye çeviri yapabilme yeteneğine sahip olan Pix2Pix ve CycleGAN yöntemleri kullanılabilir. Dezavantajları, gerçek bir bölütleme yaparken ya da görüntü oluştururken eksik pikseller oluşturması bakımından hata ile karşılaşılmaktadır.

\section{Kaynakça}

ALTUN, S., \& TALU, M. F. (2019, October). Aynı Şartlar Altında Farklı Üretici Çekişmeli Ağların Karşılaştırılması. In 2019 3rd International Symposium on Multidisciplinary Studies and Innovative Technologies (ISMSIT) (pp. 1-6). IEEE.

BARIŞKAN, M. A., Orman, Z., \& ŞAMLI, R. Common Generative Adversarial Network Types and Practical Applications. Avrupa Bilim ve Teknoloji Dergisi, 585-590.

Zhu, J. Y., Park, T., Isola, P., \& Efros, A. A. (2017). Unpaired image-to-image translation using cycle-consistent adversarial networks. In Proceedings of the IEEE international conference on computer vision (pp. 22232232).

Isola, P., Zhu, J. Y., Zhou, T., \& Efros, A. A. (2017). Image-toimage translation with conditional adversarial networks. In Proceedings of the IEEE conference on computer vision and pattern recognition (pp. 1125-1134).

Efros, A. A., \& Leung, T. K. (1999, September). Texture synthesis by non-parametric sampling. In Proceedings of the seventh IEEE international conference on computer vision (Vol. 2, pp. 1033-1038). IEEE.

Hertzmann, A., Jacobs, C. E., Oliver, N., Curless, B., \& Salesin, D. H. (2001, August). Image analogies. In Proceedings of the 28th annual conference on Computer graphics and interactive techniques (pp. 327-340).

Long, J., Shelhamer, E., \& Darrell, T. (2015). Fully convolutional networks for semantic segmentation. In Proceedings of the IEEE conference on computer vision and pattern recognition (pp. 3431-3440).

Goodfellow, I., Pouget-Abadie, J., Mirza, M., Xu, B., WardeFarley, D., Ozair, S., ... \& Bengio, Y. (2014). Generative adversarial nets. In Advances in neural information processing systems (pp. 2672-2680).

Sangkloy, P., Lu, J., Fang, C., Yu, F., \& Hays, J. (2017). Scribbler: Controlling deep image synthesis with sketch and color. In Proceedings of the IEEE Conference on Computer Vision and Pattern Recognition (pp. 5400-5409).
Karacan, L., Akata, Z., Erdem, A., \& Erdem, E. (2016). Learning to generate images of outdoor scenes from attributes and semantic layouts. arXiv preprint arXiv:1612.00215.

Sato, M., Hotta, K., Imanishi, A., Matsuda, M., \& Terai, K. (2018, January). Segmentation of Cell Membrane and Nucleus by Improving Pix2Pix. In BIOSIGNALS (pp. 216220).

Wang, X., Yan, H., Huo, C., Yu, J., \& Pant, C. (2018, August). Enhancing Pix2Pix for remote sensing image classification. In 2018 24th International Conference on Pattern Recognition (ICPR) (pp. 2332-2336). IEEE.

Gatys, L. A., Ecker, A. S., \& Bethge, M. (2016). Image style transfer using convolutional neural networks. In Proceedings of the IEEE conference on computer vision and pattern recognition (pp. 2414-2423). 